\title{
Cryptococcus gattii: Emergence in Western North America: Exploitation of a Novel Ecological Niche
}

\author{
Kausik Datta, ${ }^{1}$ Karen H. Bartlett, ${ }^{2}$ and Kieren A. Marr ${ }^{1}$ \\ ${ }^{1}$ School of Medicine, Johns Hopkins University, 720 Rutland Avenue, Room 1064, Ross Building, Baltimore, MD 21205, USA \\ ${ }^{2}$ School of Environmental Health, University of British Columbia, Vancouver, BC, Canada V6T 1Z3 \\ Correspondence should be addressed to Kieren A. Marr, kmarr4@jhmi.edu
}

Received 10 July 2008; Accepted 17 November 2008

Recommended by Bettina Fries

The relatively uncommon fungal pathogen Cryptococcus gattii recently emerged as a significant cause of cryptococcal disease in human and animals in the Pacific Northwest of North America. Although genetic studies indicated its possible presence in the Pacific Northwest for more than 30 years, C. gattii as an etiological agent was largely unknown in this region prior to 1999. The recent emergence may have been encouraged by changing conditions of climate or land use and/or host susceptibility, and predictive ecological niche modeling indicates a potentially wider spread. C. gattii can survive wide climatic variations and colonize the environment in tropical, subtropical, temperate, and dry climates. Long-term climate changes, such as the significantly elevated global temperature in the last 100 years, influence patterns of disease among plants and animals and create niche microclimates habitable by emerging pathogens. C. gattii may have exploited such a hitherto unrecognized but clement environment in the Pacific Northwest to provide a wider exposure and risk of infection to human and animal populations.

Copyright (c) 2009 Kausik Datta et al. This is an open access article distributed under the Creative Commons Attribution License, which permits unrestricted use, distribution, and reproduction in any medium, provided the original work is properly cited.

\section{Introduction: The Organism and the Disease}

Cryptococcus gattii (formerly, Cryptococcus neoformans var. gattii) [1] is a basidiomycetous yeast pathogenic to immunocompetent mammals including humans. This relatively uncommon organism differs from the congeneric, more commonly encountered pathogen, C. neoformans, with regards to phenotypic characteristics, natural habitat, epidemiology, ecology, clinical manifestations of disease, and responses to antifungal therapy [2]. Phylogenetic studies have shown that $C$. gattii and C. neoformans diverged from a common ancestor approximately 40 million years ago [3]. Hosts acquire cryptococci via inhalation, and the disease ("Cryptococcosis") caused by both C. gattii and $C$. neoformans affects the lungs, with the potential to disseminate to distant tissues, most frequently, the central nervous system, causing life-threatening meningoencephalitis [4]. Compared to C. neoformans, C. gattii infections more often cause granulomatous lesions (cryptococcomas) in lung and brain, with more associated neurological sequelae and morbidity [5-8]. Though otherwise healthy hosts presenting with meningitis respond to antifungal therapy, complete mycological cure (culture negativity) appears to be more often delayed [7, 9]. Genetic typing studies using molecular techniques have identified distinct haploid genotypes among the clinical, veterinary, and environmental isolates of $C$. gattii, namely, VGI, VGII (further subdivided into VGIIa, VGIIb [10, 11], and recently VGIIc [12]), VGIII, and VGIV [11-15]. The genotype VGIIa was preponderantly present in the emergence of C. gattii disease in 1999 on Vancouver Island and Lower Mainland of British Columbia (BC) in Canada, and has, therefore, been termed the "Vancouver Island major emergence strain"; it was found to be unique to the Pacific Northwest and hypervirulent in mouse studies $[10,11]$.

\section{C. gattii Outbreak in the Pacific Northwest}

C. gattii emerged as an agent of life-threatening infections in the Pacific Northwest of North America in 1999. Previously unknown in the region, more than 200 cases of C. gattii have now been documented in humans, and more than twice that number in domestic animals, accounting for an average annual incidence of 6.5 cases per million in BC or 27.9 
cases per million on Vancouver Island; this is the highest "endemic" incidence reported worldwide [16]. There has been a substantial mortality from this disease; between 1999 and 2006, the case fatality rate from C. gattii disease was estimated to be $4.5 \%$ [17].

Although the majority of locally acquired C. gattii cases occurred in Vancouver Island residents, since 2004 there has been a steady increase in the numbers among BC Lower Mainland residents [17] as well as among the Northwestern states in the United States (Washington and Oregon) $[10,11$, $16,18-20]$. To date, we are aware of approximately 20 cases of $C$. gattii disease diagnosed in humans in Washington and Oregon, many of whom have had no travel history to any known C. gattii-disease endemic zone (K Marr, unpublished observation). The organism has also been recovered from the environment in Washington State [16]. An overwhelming majority of these isolates belonged to the molecular genotype VGII ( 95\% VGIIa; 5\% VGIIb) and one VGIII [10-12, 14, $16,19,20]$. Though the exact mode of transport of $C$. gattii from Vancouver Island to the Lower Mainland is not known, studies of possible dispersal mechanisms have indicated association of C. gattii cases with high-traffic locations, and evidence of human-associated dispersal through wheel wells of cars, shoes, and movement of soil or wood products as well as water $[18,21]$.

Since 1999, the incidence of C. gattii infection in domestic animals has increased greatly in Western North America, in parallel with the outbreak of human cryptococcosis. C. gattii disease has been diagnosed in dogs, cats, ferrets, porpoises, alpacas and llamas, horses, and psittacine birds on Vancouver Island, BC Lower Mainland [22-24] as well as in Washington and Oregon $[12,16,20]$. Cryptococcal infection in animals occurs from inhalation of airborne infectious propagules (yeast or spores) and subsequent colonization of the nasal cavity and paranasal sinuses, often resulting in asymptomatic carriage and/or subclinical infection $[2,22]$. Subclinically infected animals may clear the organism, remain protractedly colonized and/or infected (with repeatedly positive serum for cryptococcal antigen), or progress to clinical disease [25]. Disease can be manifested by upper respiratory symptoms, subcutaneous nodules, pneumonia, central nervous system and/or ocular disorders, and lymphadenopathy $[2,24]$. A unique feature of the Pacific Northwest outbreak is the number of marine mammals, primarily porpoises, which have died with C. gattii pneumonia [24]. Over $90 \%$ of the veterinary isolates have belonged to molecular type VGIIa [16, 22-24]. Identified risk factors in animals in this region include disturbance of soil and/or human activities such as logging within $10 \mathrm{~km}$, hiking, or hunting in areas colonized with C. gattii [26].

\section{C. gattii: Establishment in a Novel Environmental Niche}

In a seminal study on the epidemiology ofcryptococcosis [27], it was noted that the majority of clinical cases of C. gattii disease occurred in people residing in hot and humid climates of the tropics and subtropics. Prior to
1999, the geographical regions with any degree of C. gattii endemicity included Australia and New Zealand, Papua New Guinea, South and Southeast Asia (Cambodia, Malaysia, Thailand, Vietnam, China, Taiwan, Singapore, Nepal, and the Indian subcontinent), parts of Latin America (Argentina, Brazil, Colombia, Uruguay, Paraguay, Peru, and Venezuela), Southern California, Mexico, Hawaii, Central and South Africa, and certain parts of Europe (Austria, Germany, France, Italy, Greece, and Spain) (reviewed in [2]; also see [28-32]).

Studies from Australia and elsewhere [2] indicate that C. gattii can colonize the environment in tropical, subtropical, temperate, and dry climates. Although C. gattii grows slower at $37^{\circ} \mathrm{C}$ compared to $C$. neoformans isolates [33], environmental isolates of C. gattii grow equally well at $30^{\circ} \mathrm{C}$ and $37^{\circ} \mathrm{C}$ - a survival property believed to be mediated in part by a manganese-containing mitochondrial superoxide dismutase (SOD2) which is induced at elevated temperatures [34]. Recent work with environmental isolates from Vancouver Island has shown that the organism, when grown in nutritionally deficient soil extract broth, uses constituents in the soil to produce melanin; these melanized cells are more resistant to UV irradiation exposure than the same strains which did not melanize when grown in $1 / 16$ th strength malt extract. The ability of this C. gattii genotype to resist UV irradiation and colonize with high concentrations in desiccated soil may contribute to the survival and dispersal of this strain in this environment [35].

The origins of the C. gattii strains, which now permanently colonize the environment on Vancouver Island, remain unknown. The provincial medical mycology collection has been examined, and no archived C. gattii isolates were identified prior to 1999. Significant global dispersal of cryptococcal strains $[14,36]$ makes accurate determination of specific origin difficult. However, genotypic analysis enabled the study of lineages of the $C$. gattii isolates, tracing the origin and evolution of the organism and establishing its relevance in the context of the outbreak. All C. gattii clinical isolates from the Vancouver Island emergence were found to contain $\alpha$ allele of the mating type-specific genes (MAT $\alpha$ ) and were sexually fertile $[11,37]$. Genotypic analysis further revealed that a rare, nonclassical, same-sex reproduction between two MAT $\alpha$ parents resulted in the VGIIa strain. These observations support the hypothesis that cryptic same-sex reproduction may have enhanced the virulence of the VGIIa genotype, helping a "hypervirulent" strain adapt to and propagate in the local environmental niche [10]. In contrast, study of Australian C. gattii populations recovered from Eucalyptus tree hollows found that the organism exists as either $\alpha$-mating-type isolates, or both a and $\alpha$-mating-type isolates, and both unisexual and heterosexual recombination produce infectious spores [38].

Because of global dispersal $[14,36]$, it is possible that the Vancouver Island major genotype VGIIa may exist elsewhere, but that remains to be established; one South American isolate thus far reported to be highly similar to VGIIa differs at one locus by multilocus sequence typing (MLST). It may well be related to the major outbreak strain, but either with a different origin (in Australia, South America, or within the 
Pacific Northwest), or by genetic drift (in transit to the Pacific Northwest, perhaps by mating with another VGII strain). On the other hand, the minor genotype VGIIb appears to be identical with fertile isolates from Australia and likely originated there [10].

In the first two Oregon cases of nontravel-associated $C$. gattii disease, C. gattii isolates genotyped as VGII, but they were genetically distinct from either VGIIa or VGIIb strains found on Vancouver Island [16] and the relationship of these cases to the outbreak is unknown. However, two archived $C$. gattii isolates from the United States, NIH444 (a.k.a. ATCC 32609 and CBS6956) and NIH B4534 (a.k.a. CBS7750), were found to be identical to the Vancouver Island VGIIa strain $[10,11]$, leading to the hypothesis that this genotype may have been present in North America for more than 30 years. Strain NIH444 was isolated from a sputum sample from a patient in Seattle, Washington, in the early 1970s, and strain NIH B4534 was recovered from a Eucalyptus tree in San Francisco in 1992. It is important to note that we do not have a complete travel history from the Seattle patient. However, if this isolate has been in the environment in Western North America for this long, other factors, such as changing conditions of climate or land use and/or host susceptibility, have appeared to encourage its emergence in more recent years.

\section{Climate Change and Disease Relationship: Overview}

In the last 100 years (1906-2005), the global temperature has increased by $0.74[\mathrm{CI}, 0.56-0.92]^{\circ} \mathrm{C}$; and the linear warming trend over the last 50 years $\left(0.13[\mathrm{CI}, 0.10-0.16]^{\circ} \mathrm{C}\right.$ per decade) is nearly twice that for the last 100 years [39]. The last three decades have seen an unprecedented escalation of global warming - both at the level of the middle troposphere and the surface-a large part of it being anthropogenic through emission of greenhouse gases. Long-term changes in climate and subsequent effects have been observed at continental, regional, and ocean basin scales, including changes in Arctic temperatures and ice, widespread changes in humidity and precipitation amounts, ocean level and salinity, wind patterns, and aspects of extreme weather including droughts, heavy precipitation, heat waves, and the intensity of tropical cyclones. It has been predicted that the earth in the 21 st century will face some $2^{\circ} \mathrm{C}\left(3.5^{\circ} \mathrm{F}\right)$ or more in additional warming [39]. However, the rate of change between microenvironments varies substantially, with polar zones changing more quickly while other zones remain relatively stable, and therefore, global averages cannot be used to predict effects of microclimates. Since 1948, the average annual temperatures at one site on the eastern coast of Vancouver Island increased by $1.44^{\circ} \mathrm{C}$ which is a statistically significant change $(P<.001)$ (data obtained from Environment Canada). Unfortunately, many government sponsored meteorological stations have been abandoned, leaving research scientists with the arduous task of documenting microclimate variation.

Speculative studies on how a widespread climate change, specifically the elevation of global temperature, might affect the distribution of infectious diseases began about two decades ago. Health outcomes of climate change are diverse, and depend upon many different factors with respect to biodiversity, nutrient cycle, physical relocation, internal defense systems, and transmission dynamics within microbes [40]. The initial studies almost exclusively focused on vectorborne diseases, predicting possible vector movements with rise in temperature in erstwhile temperate zones. However, the relationship between climate change and infectious disease is inherently complex, and not easily amenable to predictive epidemiology. For example, the impact of climate change on infectious disease is not restricted to vectorborne diseases or infections that affect human health directly. Climate change may influence patterns of disease among plants and animals, impacting the human food supply (and thereby reducing human resistance to infections), or indirectly causing human disease patterns to shift, as the host range for disease reservoirs may change because of human migration to geographically disparate areas and/or changes in abundance and distribution of disease vectors and agents [40-42].

In 2004, the World Health Organization (WHO) published a study of the global disease burden attributable to human-induced climate change up to the year 2000, and made quantitative model-based predictions of climate change-associated health risks up to 2030 [43]. Despite the lack of comprehensive models for various specific climatedisease relationships, overall results indicate that even the subtle climatic changes occurring since the mid-1970s could be responsible for over 150000 deaths from climate-sensitive diseases, and approximately 5 million disability-adjusted life years each year-the most vulnerable being the poorer regions of the world, according to WHO estimates, although climate change poses a global threat to public health [43]. Diseases with which significant association of climate changes has already been observed include water- and foodborne diseases (such as cryptosporidial diarrhea, salmonellosis, algal toxicity, and cholera), vector-borne diseases (such as malaria, Chagas disease, borreliosis, schistosomiasis, and dengue), rodent-borne diseases (such as leptospirosis) as well as infections caused by the St. Louis Encephalitis virus and the West Nile virus, both of which have been shown to prefer warmer climates [42]. The global warming phenomenon has, in addition, been associated with various other noninfectious diseases with significant human morbidity, including chronic respiratory ailments, cardiovascular diseases, neurological and psychiatric disorders as well as those pertaining to occupational health [44]. According to the WHO estimates of morbidity and mortality associated with anthropogenic climate change, the year 2030 would see a doubling of excess risk of the various health outcomes [43].

\section{C. gattii: Change of Environmental Niche or Adaptation to a New One}

In Australia, in the early 1990s, Ellis and Pfeiffer observed a correlation between the distributions of human cryptococcal disease and of Eucalyptus trees $[45,46]$, whose bark is rich in 
dihydroxyphenylalanine (L-DOPA), a substance metabolized by Cryptococcus species to produce melanin; this has been hypothesized to contribute to their environmental survival [47, 48]. Association of C. gattii with Eucalyptus has been sporadically reported from India, Brazil, Italy, and the United States [49-52]. However, the absence of this association with Eucalyptus in other endemic areas, such as the Northern Territory of Australia [53], Papua New Guinea [54], Central and South Africa [55], Brazil, and Malaysia as well as the isolation of C. gattii from non-Eucalyptus trees and tree materials [56-60], indicates the existence of additional environmental sources. Since it was first discovered to have a stable ecological niche on Vancouver Island in 2002, C. gattii has consistently been recovered in high concentration from native trees, soil, air, freshwater, and seawater $[16,19]$.

Does the Vancouver Island outbreak, then, point to a changing ecological niche for this organism in Western North America? From the beginning of the C. gattii epidemic on Vancouver Island and adjoining areas, epidemiological studies showed that all humans and animals with cryptococcal infection either lived within or traveled to areas identified by unique weather and vegetation zones. The British Columbia Ministry of Forests categorizes areas with similar ecologies within the province by biogeoclimatic zone designations. A biogeoclimatic zone is a geographical area with an ecosystem comprised of a relatively uniform macroclimate, defined vegetation, soils, and animal life inhabiting that climate, and may contain smaller ecosystems (subzones) that reflect differences in regional climate, soil moisture, soil nutrient status, and environmental disturbance [61]. The unique zones along the eastern edge of Vancouver Island are in the rain shadow of the Olympic Mountains located in Washington State to the south, and include the Coastal Douglas Fir (CDF) and very dry Coastal Western Hemlock $(\mathrm{CWH})$ biogeoclimatic zones. The $\mathrm{CDF}$ and very dry $\mathrm{CWH}$ zones are characterized by warm, dry summers (average summer temperature $15.6 \pm 1.24^{\circ} \mathrm{C} ; 190.24 \pm 55.5 \mathrm{~mm}$ rain), and mild, wet winters (average winter temperature $5.77 \pm 0.64^{\circ} \mathrm{C} ; 884.33 \pm 206.22 \mathrm{~mm}$ rain). C. gattii has been repeatedly and consistently isolated from the environment in these biogeoclimatic zones $[16,19,22]$. The CDF and CWH zones also include the Southern Gulf Islands and portions of the BC Lower Mainland. Similar climates with comparable temperature and rainfall extend further south into Washington and Oregon in the United States. The San Juan Islands, Puget Sound in Washington, and the Willamette Valley in Oregon harbor ecologically similar plant diversity as in $\mathrm{BC}$, lending support to the idea that environmental niches suitable for colonization by C. gattii, are present in Western North America [16]. Indeed, largescale environmental sampling performed during 2001-2005 on the BC mainland, the Gulf Islands, and Washington revealed that $3 \%$ of 2033 off-Vancouver Island samples of air, water, soil, and trees were positive for C. gattii serotype B (mostly VGIIa, except two VGIs) [16].

Environmental sampling studies on Vancouver Island revealed high concentrations of $C$. gattii in the soil, indicating a potential source of exposure [18], and data gathered from the BC environment conclusively demonstrate that C. gattii is well adapted for survival in a dry, nutrient-deprived soil and is more likely to spread as airborne propagules during dry summer weather [19]. However, whereas $C$. gattii was consistently isolated from localized areas, it was not found, or was below the limit of detection in other areas, such as the San Juan Islands [62], despite ecological similarity to identified zones of endemicity in Vancouver Island and BC Lower Mainland. This suggests that there may be environmental "hotspots", that is, zones of high concentration, of C. gattii within the same broad ecological niches. There are also areas with transient colonization, with sites intermittently positive over time, and some sites which initially tested negative which subsequently either became colonized, or the concentration rose above the limit of detection [18, 19]. Whether microclimatic conditions govern the creation and maintenance of these hotspots is not known, but the fact remains that C. gattii now inhabits a stable ecologic niche in the environment of the Pacific Northwest in concentrations high enough to pose a risk of infection through environmental exposures. Prior to the outbreak of $C$. gattii disease, there was no reason to seek its presence in the environment, as there were no cases of locally acquired infection, and C. gattii is not a phytopathogen. The relationships between an emerging pathogen and the environment are not often studied, and it is even rarer that researchers have been able to document the emergence with as much detail as has been possible in this $\mathrm{BC}$ outbreak. The unexpectedly rich dataset obtained from BC environmental and epidemiological ecologies can be used to inform future eco-health investigations. In this case, the existence of libraries of cryptococcal strains from global clinical and environmental origins provided the resources for swift characterization and molecular epidemiology of the causative organism; this information changed forever the simplistic idea of unvarying geographic boundaries on infectious organisms.

A promising tool which can be used by climatologists working with epidemiologists to predict public health impacts is ecological niche modeling [63-65]. These computer simulations take into account ecosystems, meteorology, and the presence of pathogens in the environment to predict areas with similar ecologies that may be at risk of pathogen spread. A recently completed thesis from the University of British Columbia using the Generic Algorithm for Rule-set Prediction (GARP) modeled the potential for C. gattii to spread to other areas of the Pacific Northwest [66]. Using existing data from human and animal clinical cases and Geographic Information System (GIS) coordinates of colonized environmental sites [18, 19, 21, 24], the model predicts a larger area of potential colonization than is currently the case. The predicted area includes cities with large populations (over 4 million). Since this model was developed, there have been at least four-human, eightanimal, and four-environmental samples of $C$. gattii recovered from the predicted zone which was not on Vancouver Island $[16,17,20]$. By the same token, the vastly larger land mass of British Columbia is predicted not to become colonized with C. gattii in the foreseeable future due to the 
extremes of temperature, snow cover, or lack of suitable habitat [66].

C. gattii, similar to the congeneric pathogen C. neoformans, has evolved mechanisms which protect it from the environment. For example, the melanin production by these organisms contributes to the protection from the ultraviolet radiation in sunlight. The predominant genotype of the Vancouver Island outbreak thrives in dry, nutrient poor soil at high concentrations. It appears to be well adapted for this marginal microecologic zone [19]. In Colombia, for example, the dispersal of C. gattii is greater during periods of high humidity or rain [67]. In Australia, the airborne distribution of propagules is associated with the flowering season of Eucalyptus [68]. Neither of these conditions describes the experience of the British Colombian genotypes VGIIa or VGIIb, which suggests that the organism is successful in this new ecologic niche because it can adapt preexisting characteristics to fill novel, underutilized microscopic niches, rather than strictly requiring a constrained environment. Even the widely held view that $C$. gattii was restricted to a symbiotic relationship with Eucalyptus trees has since been shown not to be the case, as C. gattii regularly colonizes native trees in countries outside Australia [57, 58, 69].

Cyclical climate change patterns (called "oscillations") are driven by forces such as solar cycles and the ocean currents characterized by the El Niño and La Niña years, whereas more long-term changes, such as an elevation of global temperatures, must be measured over decades or centuries. Therefore, the problem of association of climate changes with the epidemiology of various infectious diseases is twofold. Climate changes may be long term, with the potential to cause significant epidemiological changes over long-time horizons, or the climate may suddenly shift, changing patterns and spread of exposure in a given climatic zone. Both of these possibilities pose challenges to public health studies.

That C. gattii emerged as a human and animal pathogen in the late 1990s, in a new habitat, is indisputable. Whether or not the climatic conditions (both short- and long-term) in the new habitat made it conducive for the organism to do so is under debate. The oscillatory climate change patterns preceding the emergence were similar to the patterns seen in this area over the last 30 years. The years 1992-1994 and 1998-2003 were dryer than the 30-year average during the summer, followed by the years 1997, 2004, and 2005, which had higher-than-average summer rainfall; the winter rains roughly followed the same pattern. Importantly, however, the amount of snow coverage on southern Vancouver Island and the CDF biogeoclimatic zone decreased over the same time period. This constantly repeating dry/wet pattern in conjunction with the elevation of temperature may well be a driving factor in the prolongation of C. gattii as a pathogen in this geographic location. However, given the paucity of long-term data on C. gattii emergence in relation to climate changes, it is difficult to attribute the emergence entirely to climate change. A proof-of-concept example supporting the notion is Coccidioides immitis, an environmental organism which proliferates in wet years and is widely dispersed in dry years, causing localized spikes in hospitalization for areas adjacent to endemic locations [70]. For C. gattii, some factor(s) (climate, land use, human agency, etc.) must have become permissive to the permanent colonization of the organism in high enough concentration to cause disease with an incidence rate of around 28 cases/million population (on Vancouver Island alone) [16]. Identification of those factors would help formulate preventive public health approaches.

It is also clear that C. gattii disease has escalated to an "off island" problem as well, involving the Northwestern US (Washington and Oregon). The extent of disease and the distribution of the cryptococcal isolates within the United States are unknown, and will remain underappreciated until laboratory methods to identify and speciate the isolates, standardized reporting of disease, and environmental studies are established.

C. gattii already had the ability to survive in a wide range of environmental variations, but the Western North America outbreak teaches us that it may exploit hitherto unrecognized but clement environments and provide a wider exposure, and thereby, risk of infection to the human and animal populations. The challenge for public health is to coordinate efforts toward early recognition of the emergence of new or reemergence of previously encountered infectious diseases to alert primary health care providers as to the diagnosis and appropriate treatment in order to prevent excess morbidity and mortality. However, understanding the consequences of ecological change is a group effort which includes health researchers, climatologists, and ultimately global citizens whose health may depend on the capacity to adapt to a rapidly changing environment.

\section{References}

[1] K. J. Kwon-Chung and A. Varma, "Do major species concepts support one, two or more species within Cryptococcus neoformans?" FEMS Yeast Research, vol. 6, no. 4, pp. 574-587, 2006.

[2] T. C. Sorrell, "Cryptococcus neoformans variety gattii," Medical Mycology, vol. 39, no. 2, pp. 155-168, 2001.

[3] L. T. Campbell, J. A. Fraser, C. B. Nichols, F. S. Dietrich, D. Carter, and J. Heitman, "Clinical and environmental isolates of Cryptococcus gattii from Australia that retain sexual fecundity," Eukaryotic Cell, vol. 4, no. 8, pp. 1410-1419, 2005.

[4] J. R. Perfect and A. Casadevall, "Cryptococcosis," Infectious Disease Clinics of North America, vol. 16, no. 4, pp. 837-874, 2002.

[5] R. A. Seaton, N. Verma, S. Naraqi, J. P. Wembri, and D. A. Warrell, "Visual loss in immunocompetent patients with Cryptococcus neoformans var. gattii meningitis," Transactions of the Royal Society of Tropical Medicine and Hygiene, vol. 91, no. 1, pp. 44-49, 1997.

[6] P. Grosse, K. Tintelnot, O. Söllner, and B. Schmitz, "Encephalomyelitis due to Cryptococcus neoformans var gattii presenting as spinal tumour: case report and review of the literature," Journal of Neurology, Neurosurgery and Psychiatry, vol. 70, no. 1, pp. 113-116, 2001.

[7] D. H. Mitchell, T. C. Sorrell, A. M. Allworth, et al., "Cryptococcal disease of the CNS in immunocompetent hosts: influence of cryptococcal variety on clinical manifestations and outcome," Clinical Infectious Diseases, vol. 20, no. 3, pp. 611-616, 1995. 
[8] S. Chen, T. Sorrell, G. Nimmo, et al., "Epidemiology and host- and variety-dependent characteristics of infection due to Cryptococcus neoformans in Australia and New Zealand. Australasian Cryptococcal Study Group," Clinical Infectious Diseases, vol. 31, no. 2, pp. 499-508, 2000.

[9] R. López-Martínez, J. L. Soto-Hernández, L. OstroskyZeichner, L. R. Castañón-Olivares, V. Angeles-Morales, and J. Sotelo, "Cryptococcus neoformans var. gattii among patients with cryptococcal meningitis in Mexico. First observations," Mycopathologia, vol. 134, no. 2, pp. 61-64, 1996.

[10] S. E. Kidd, F. Hagen, R. L. Tscharke, et al., "A rare genotype of Cryptococcus gattii caused the cryptococcosis outbreak on Vancouver Island (British Columbia, Canada)," Proceedings of the National Academy of Sciences of the United States of America, vol. 101, no. 49, pp. 17258-17263, 2004.

[11] J. A. Fraser, S. S. Giles, E. C. Wenink, et al., "Same-sex mating and the origin of the Vancouver Island Cryptococcus gattii outbreak," Nature, vol. 437, no. 7063, pp. 1360-1364, 2005.

[12] E. J. Byrnes, R. Bildfell, S. A. Frank, T. G. Mitchell, K. Marr, and J. Heitman, "Molecular evidence that the Vancouver Island Cryptococcus gattii outbreak has expanded into the United States Pacific Northwest," The Journal of Infectious Diseases. In press.

[13] S. E. Kidd, H. Guo, K. H. Bartlett, J. Xu, and J. W. Kronstad, "Comparative gene genealogies indicate that two clonal lineages of Cryptococcus gattii in British Columbia resemble strains from other geographical areas," Eukaryotic Cell, vol. 4, no. 10, pp. 1629-1638, 2005.

[14] M. Bovers, F. Hagen, and T. Boekhout, "Diversity of the Cryptococcus neoformans-Cryptococcus gattii species complex," Revista Iberoamericana de Micología, vol. 25, no. 1, pp. S4-S12, 2008.

[15] T. C. Sorrell, S. C. A. Chen, P. Ruma, et al., "Concordance of clinical and environmental isolates of Cryptococcus neoformans var. gattii by random amplification of polymorphic DNA analysis and PCR fingerprinting," Journal of Clinical Microbiology, vol. 34, no. 5, pp. 1253-1260, 1996.

[16] L. MacDougall, S. E. Kidd, E. Galanis, et al., "Spread of Cryptococcus gattii in British Columbia, Canada, and detection in the Pacific Northwest, USA," Emerging Infectious Diseases, vol. 13, no. 1, pp. 42-50, 2007.

[17] BC Centre for Disease Control, "BC Cryptococcus gattii Surveillance Summary, 1999-2006," November 2008, http://www.bccdc.org/topic.php?item=109.

[18] S. E. Kidd, Y. Chow, S. Mak, et al., "Characterization of environmental sources of the human and animal pathogen Cryptococcus gattii in British Columbia, Canada, and the Pacific Northwest of the United States," Applied and Environmental Microbiology, vol. 73, no. 5, pp. 1433-1443, 2007.

[19] A. Upton, J. A. Fraser, S. E. Kidd, et al., "First contemporary case of human infection with Cryptococcus gattii in Puget sound: evidence for spread of the Vancouver Island outbreak," Journal of Clinical Microbiology, vol. 45, no. 9, pp. 3086-3088, 2007.

[20] K. H. Bartlett, S. E. Kidd, and J. W. Kronstad, "The emergence of Cryptococcus gattii in British Columbia and the Pacific Northwest," Current Infectious Disease Reports, vol. 10, no. 1, pp. 58-65, 2008.

[21] S. E. Kidd, P. J. Bach, A. O. Hingston, et al., "Cryptococcus gattii dispersal mechanisms, British Columbia, Canada," Emerging Infectious Diseases, vol. 13, no. 1, pp. 51-57, 2007.

[22] C. Stephen, S. Lester, W. Black, M. Fyfe, and S. Raverty, "Multispecies outbreak of cryptococcosis on southern Vancouver
Island, British Columbia," Canadian Veterinary Journal, vol. 43, no. 10, pp. 792-794, 2002.

[23] S. J. Lester, N. J. Kowalewich, K. H. Bartlett, M. B. Krockenberger, T. M. Fairfax, and R. Malik, "Clinicopathologic features of an unusual outbreak of cryptococcosis in dogs, cats, ferrets, and a bird: 38 cases (January to July 2003)," Journal of the American Veterinary Medical Association, vol. 225, no. 11, pp. 1716-1722, 2004.

[24] C. G. Duncan, C. Stephen, S. Lester, and K. H. Bartlett, "Subclinical infection and asymptomatic carriage of Cryptococcus gattii in dogs and cats during an outbreak of cryptococcosis," Medical Mycology, vol. 43, no. 6, pp. 511-516, 2005.

[25] C. G. Duncan, C. Stephen, S. Lester, and K. H. Bartlett, "Follow-up study of dogs and cats with asymptomatic Cryptococcus gattii infection or nasal colonization," Medical Mycology, vol. 43, no. 7, pp. 663-666, 2005.

[26] C. G. Duncan, C. Stephen, and J. Campbell, "Evaluation of risk factors for Cryptococcus gattii infection in dogs and cats," Journal of the American Veterinary Medical Association, vol. 228, no. 3, pp. 377-382, 2006.

[27] K.J. Kwon-Chung and J. E. Bennett, "Epidemiologic differences between the two varieties of Cryptococcus neoformans," American Journal of Epidemiology, vol. 120, no. 1, pp. 123-130, 1984.

[28] T. H. Koh, A. L. Tan, Y. L. Lo, and H. Oh, "Cryptococcus neoformans var. gattii meningitis in Singapore," Medical Mycology, vol. 40, no. 2, pp. 221-223, 2002.

[29] S. Chaturvedi, M. Dyavaiah, R. A. Larsen, and V. Chaturvedi, "Cryptococcus gattii in AIDS patients, southern California," Emerging Infectious Diseases, vol. 11, no. 11, pp. 1686-1692, 2005.

[30] M. F. Colom, S. Frasés, C. Ferrer, et al., "First case of human cryptococcosis due to Cryptococcus neoformans var. gattii in Spain," Journal of Clinical Microbiology, vol. 43, no. 7, pp. 3548-3550, 2005.

[31] U. Banerjee, K. Datta, T. Majumdar, and K. Gupta, "Cryptococcosis in India: the awakening of a giant?" Medical Mycology, vol. 39, no. 1, pp. 51-67, 2001.

[32] M. A. Viviani, M. Cogliati, M. C. Esposto, et al., "Molecular analysis of 311 Cryptococcus neoformans isolates from a 30month ECMM survey of cryptococcosis in Europe," FEMS Yeast Research, vol. 6, no. 4, pp. 614-619, 2006.

[33] K. J. Kwon-Chung and J. E. Bennett, "Cryptococcosis," in Medical Mycology, pp. 397-445, Lee and Febiger, Philadelphia, Pa, USA, 1992.

[34] S. D. Narasipura, V. Chaturvedi, and S. Chaturvedi, "Characterization of Cryptococcus neoformans variety gattii SOD2 reveals distinct roles of the two superoxide dismutases in fungal biology and virulence," Molecular Microbiology, vol. 55, no. 6, pp. 1782-1800, 2005.

[35] C. Ge, K. H. Bartlett, and R. J. Bandone, "Growth of Cryptococcus gattii in minimal culture media and susceptibility of melanized cells against UV irradiation," in Proceedings of the 7th International Conference on Cryptococcus and Cryptococcosis (ICCC '08), Nagasaki, Japan, September 2008, P-A-29.

[36] J. Xu, R. Vilgalys, and T. G. Mitchell, "Multiple gene genealogies reveal recent dispersion and hybridization in the human pathogenic fungus Cryptococcus neoformans," Molecular Ecology, vol. 9, no. 10, pp. 1471-1481, 2000.

[37] J. A. Fraser, R. L. Subaran, C. B. Nichols, and J. Heitman, "Recapitulation of the sexual cycle of the primary fungal 
pathogen Cryptococcus neoformans var. gattii: implications for an outbreak on Vancouver Island, Canada," Eukaryotic Cell, vol. 2, no. 5, pp. 1036-1045, 2003.

[38] N. Saul, M. Krockenberger, and D. Carter, "Evidence of recombination in mixed-mating-type and $\alpha$-only populations of Cryptococcus gattii sourced from single Eucalyptus tree hollows," Eukaryotic Cell, vol. 7, no. 4, pp. 727-734, 2008.

[39] C. F. Keller, "Global warming 2007 an update to global warming: the balance of evidence and its policy implications," The Scientific World Journal, vol. 7, pp. 381-399, 2007.

[40] P. R. Epstein and A. Leaf, "Biologic and medical implications of global warming," in Environmental and Occupational Medicine, W. N. Rom, Ed., pp. 1625-1637, Lippincott-Raven, Philadelphia, Pa, USA, 3rd edition, 1998.

[41] J. A. Patz and S. H. Olson, "Climate change and health: global to local influences on disease risk," Annals of Tropical Medicine and Parasitology, vol. 100, no. 5-6, pp. 535-549, 2006.

[42] A. A. Khasnis and M. D. Nettleman, "Global warming and infectious disease," Archives of Medical Research, vol. 36, no. 6, pp. 689-696, 2005.

[43] A. J. McMichael, D. H. Campbell-Lendrum, S. Kovats, et al., "Global climate change," in Comparative Quantification of Health Risks: Global and Regional Burden of Disease due to Selected Major Risk Factors, M. Ezzati, A. D. Lopez, A. Rodgers, and C. J. L. Murray, Eds., pp. 1543-1649, World Health Organization (WHO), Geneva, Switzerland, 2004.

[44] D. Yoganathan and W. N. Rom, "Medical aspects of global warming," American Journal of Industrial Medicine, vol. 40, no. 2, pp. 199-210, 2001.

[45] D. H. Ellis and T. J. Pfeiffer, "Natural habitat of Cryptococcus neoformans var. gattii," Journal of Clinical Microbiology, vol. 28, no. 7, pp. 1642-1644, 1990.

[46] T. J. Pfeiffer and D. H. Ellis, "Environmental isolation of Cryptococcus neoformans var. gattii from Eucalyptus tereticornis," Journal of Medical and Veterinary Mycology, vol. 30, no. 5, pp. 407-408, 1992.

[47] D. C. McFadden and A. Casadevall, "Capsule and melanin synthesis in Cryptococcus neoformans," Medical Mycology Supplement, vol. 39, no. 1, pp. 19-30, 2001.

[48] B. L. Gómez and J. D. Nosanchuk, "Melanin and fungi," Current Opinion in Infectious Diseases, vol. 16, no. 2, pp. 9196, 2003.

[49] H. Montenegro and C. R. Paula, "Environmental isolation of Cryptococcus neoformans var. gattii and C. neoformans var. neoformans in the city of São Paulo, Brazil," Medical Mycology, vol. 38, no. 5, pp. 385-390, 2000.

[50] E. Campisi, F. Mancianti, G. Pini, E. Faggi, and G. Gargani, "Investigation in central Italy of the possible association between Cryptococcus neoformans var. gattii and Eucalyptus camaldulensis," European Journal of Epidemiology, vol. 18, no. 4, pp. 357-362, 2003.

[51] H. C. Gugnani, T. G. Mitchell, A. P. Litvintseva, et al., "Isolation of Cryptococcus gattii and Cryptococcus neoformans var. grubii from the flowers and bark of Eucalyptus trees in India," Medical Mycology, vol. 43, no. 6, pp. 565-569, 2005.

[52] A. Chakrabarti, M. Jatana, P. Kumar, L. Chatha, A. Kaushal, and A. A. Padhye, "Isolation of Cryptococcus neoformans var. gattii from Eucalyptus camaldulensis in India," Journal of Clinical Microbiology, vol. 35, no. 12, pp. 3340-3342, 1997.

[53] S. C. A. Chen, B. J. Currie, H. M. Campbell, et al., "Cryptococcus neoformans var. gattii infection in northern Australia: existence of an environmental source other than known host eucalypts," Transactions of the Royal Society of Tropical Medicine and Hygiene, vol. 91, no. 5, pp. 547-550, 1997.

[54] I. F. Laurenson, D. G. Lalloo, S. Naraqi, et al., "Cryptococcus neoformans in Papua New Guinea: a common pathogen but an elusive source," Journal of Medical and Veterinary Mycology, vol. 35, no. 6, pp. 437-440, 1997.

[55] B. I. F. Batchelor, R. J. Brindle, and P. G. Waiyaki, "Clinical isolates of HIV-associated cryptococcosis in Nairobi, Kenya," Transactions of the Royal Society of Tropical Medicine and Hygiene, vol. 88, no. 1, p. 85, 1994.

[56] S. Huérfano, A. Castañeda, and E. Castañeda, "Experimental infection of almond trees seedlings (Terminalia catappa) with an environmental isolate of Cryptococcus neoformans var. gattii, serotype C," Revista Iberoamericana de Micologia, vol. 18, no. 3, pp. 131-132, 2001.

[57] N. Grover, S. R. Nawange, J. Naidu, S. M. Singh, and A. Sharma, "Ecological niche of Cryptococcus neoformans var. grubii and Cryptococcus gattii in decaying wood of trunk hollows of living trees in Jabalpur City of Central India," Mycopathologia, vol. 164, no. 4, pp. 159-170, 2007.

[58] Z. U. Khan, H. S. Randhawa, T. Kowshik, A. Chowdhary, and R. Chandy, "Antifungal susceptibility of Cryptococcus neoformans and Cryptococcus gattii isolates from decayed wood of trunk hollows of Ficus religiosa and Syzygium cumini trees in north-western India," Journal of Antimicrobial Chemotherapy, vol. 60, no. 2, pp. 312-316, 2007.

[59] S. T. Fortes, M. S. Lazéra, M. M. Nishikawa, R. G. L. Macedo, and B. Wanke, "First isolation of Cryptococcus neoformans var. gattii from a native jungle tree in the Brazilian Amazon rainforest," Mycoses, vol. 44, no. 5-6, pp. 137-140, 2001.

[60] M. S. Lazéra, M. A. S. Cavalcanti, L. Trilles, M. M. Nishikawa, and B. Wanke, "Cryptococcus neoformans var. gattii-evidence for a natural habitat related to decaying wood in a pottery tree hollow," Medical Mycology, vol. 36, no. 2, pp. 119-122, 1998.

[61] Research Branch of British Columbia Ministry of Forests and Range, "Biogeoclimatic Ecosystem Classification Codes and Names - BECdb (Version April 2008)," November 2008, http://www.for.gov.bc.ca/hre/becweb/resources/codesstandards/standards-becdb.html.

[62] J. A. Fraser, S. M. Lim, S. Diezmann, et al., "Yeast diversity sampling on the San Juan Islands reveals no evidence for the spread of the Vancouver Island Cryptococcus gattii outbreak to this locale," FEMS Yeast Research, vol. 6, no. 4, pp. 620-624, 2006.

[63] A. Guisan and W. Thuiller, "Predicting species distribution: offering more than simple habitat models," Ecology Letters, vol. 8, no. 9, pp. 993-1009, 2005.

[64] A. T. Peterson, "Ecologic niche modeling and spatial patterns of disease transmission," Emerging Infectious Diseases, vol. 12, no. 12, pp. 1822-1826, 2006.

[65] M. Pidwirny, "Concept of ecological niche," in Fundamentals of Physical Geography, 2nd edition, November 2008, http://www.physicalgeography.net/fundamentals/9g.html.

[66] S. Mak, Ecological niche modeling of Cryptococcus gattii in British Columbia, Canada, M.S. dissertation, University of British Columbia, Vancouver, Canada, 2007.

[67] D. P. Granados and E. Castañeda, "Influence of climatic conditions on the isolation of members of the Cryptococcus neoformans species complex from trees in Colombia from 1992-2004," FEMS Yeast Research, vol. 6, no. 4, pp. 636-644, 2006. 
[68] D. H. Ellis and T. J. Pfeiffer, "Ecology, life cycle, and infectious propagule of Cryptococcus neoformans," The Lancet, vol. 336, no. 8720, pp. 923-925, 1990.

[69] D. P. Granados and E. Castañeda, "Isolation and characterization of Cryptococcus neoformans varieties recovered from natural sources in Bogotá, Colombia, and study of ecological conditions in the area," Microbial Ecology, vol. 49, no. 2, pp. 282-290, 2005.

[70] C. S. Zender and J. Talamantes, "Climate controls on valley fever incidence in Kern County, California," International Journal of Biometeorology, vol. 50, no. 3, pp. 174-182, 2006. 


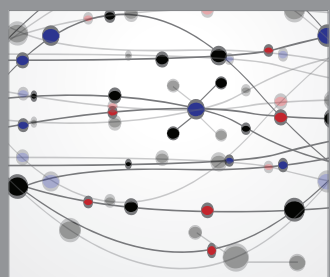

The Scientific World Journal
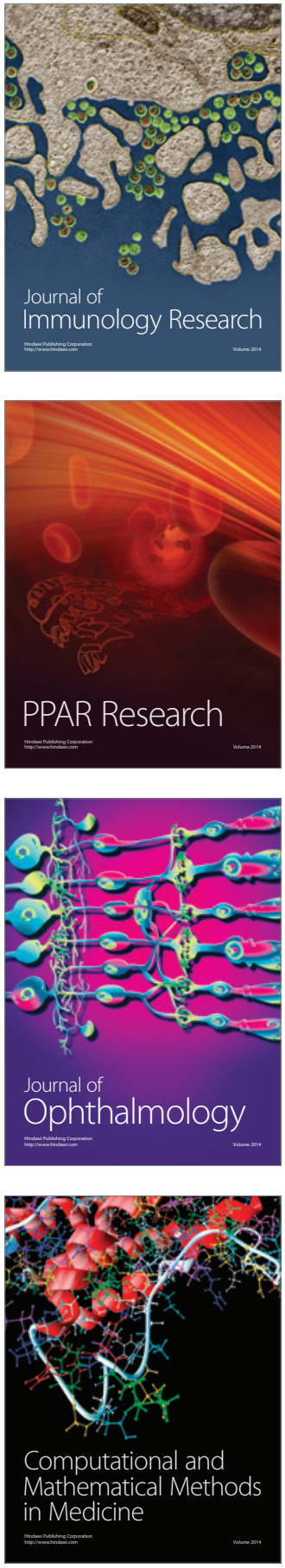

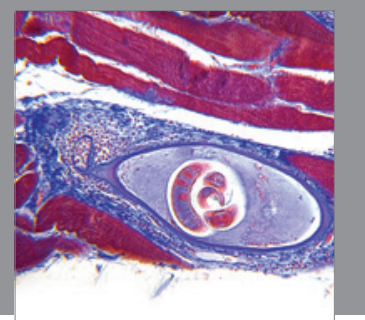

Gastroenterology

Research and Practice
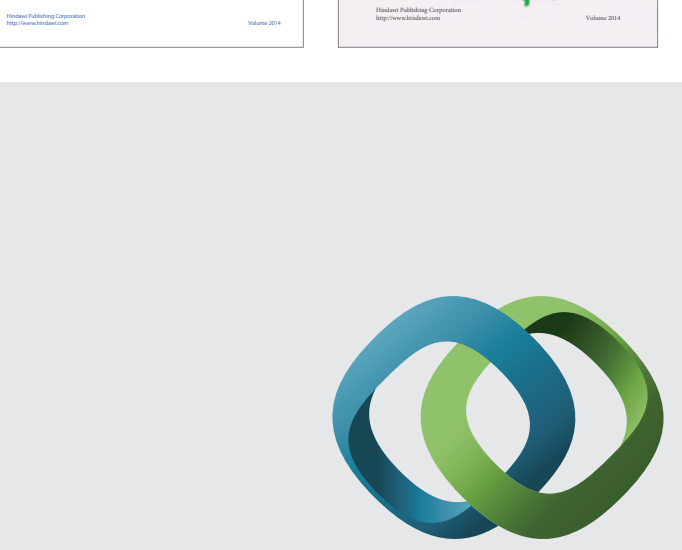

\section{Hindawi}

Submit your manuscripts at

http://www.hindawi.com
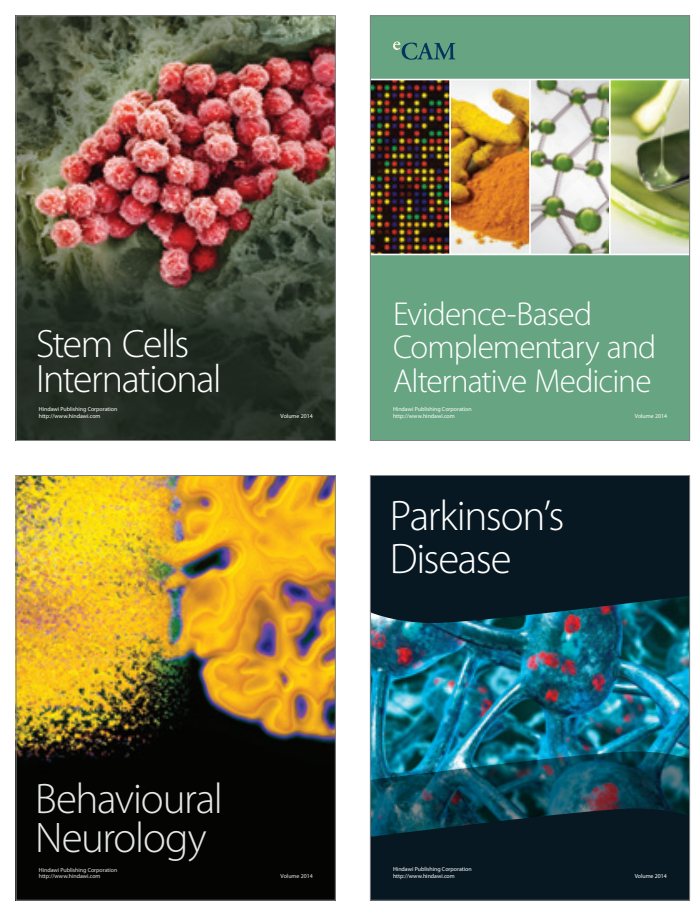

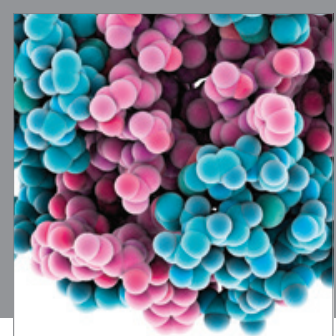

Journal of
Diabetes Research

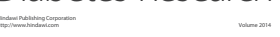

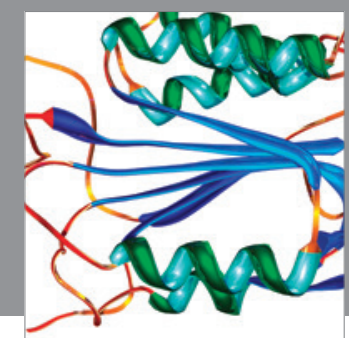

Disease Markers
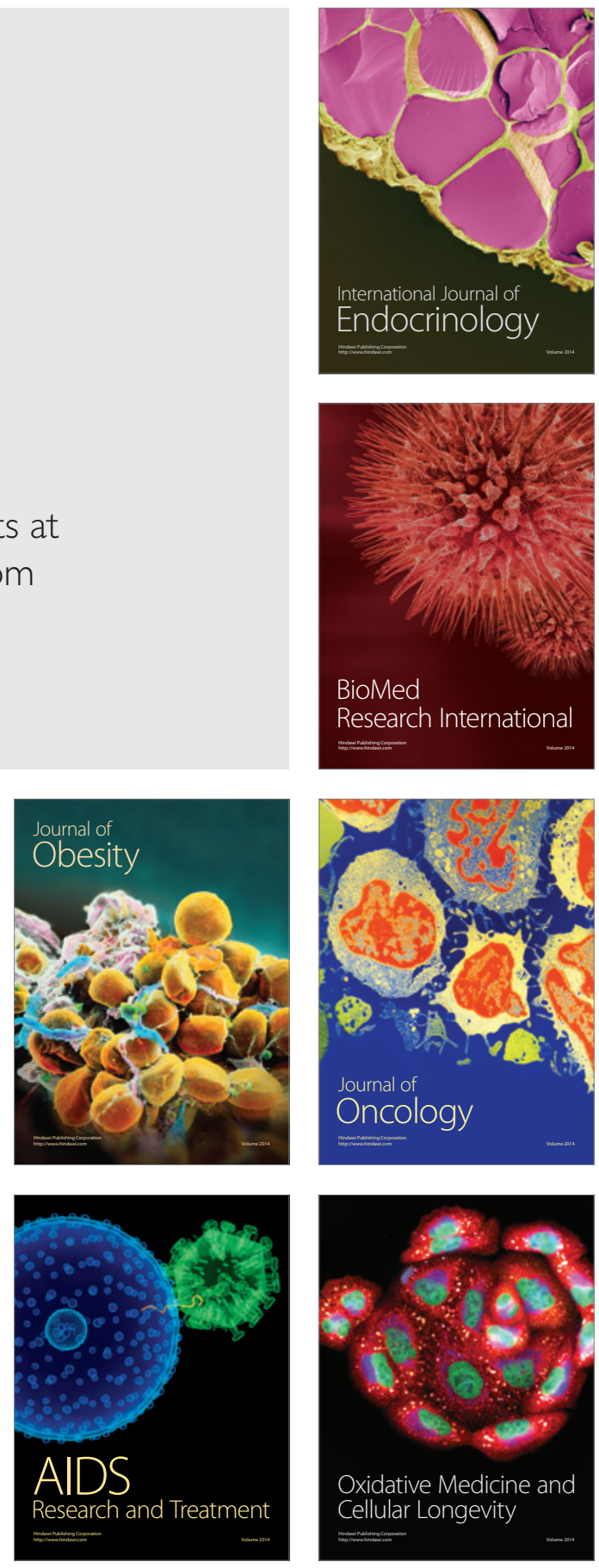